\title{
THE NORMAL BLOOD CLOTTING TIME IN THE LIGHT OF EXPERIENCE WITH THE "TWO-SYRINGE" TECHNIQUE
}

\author{
BY \\ J. GORDON ALEXANDER \\ From the Pathological Laboratory, De la Pole Hospital, Willerby, Yorks
}

(RECEIVED FOR PUBLICATION FEBRUARY 3, 1955)

The surgeon who requests the pathological laboratory to determine a patient's blood clotting time expects a result which will indicate if surgery might be dangerous. If he follows the teaching of Cummine and Lyons (1948) or of Dutton (1954) he may wish to use the test to anticipate thromboembolic episodes. The physician may request the test for various reasons. It is, accordingly, very important to know the upper limit of normal, which is stated by Wintrobe (1951) to be 15 minutes using the method of Lee and White (1913). Other textbooks give lower figures. Friedman, Schwartz, and Vincenti (1952), using a two-tube Lee-and-White technique, made the range of normal 7 to 25 minutes. They regarded the test as affording "little if any useful function in evaluating the clotting mechanism, especially in relation to the bleeding and clotting tendencies."

The work of Allen and Attyah (1953) suggested a possible explanation of these inconsistencies. These workers claimed that, even when a vein was entered with minimal trauma, blood withdrawn into the first syringe clotted sooner than that withdrawn subsequently into a second syringe. Normal medical students were used in their investigations. With large-calibre short tubes (internal diameter $9.5 \mathrm{~mm}$., height $40 \mathrm{~mm}$.) and 10 ml. syringes with 20-gauge needles, they showed that the coagulation time of the blood in the second syringe was significantly longer than that in the first. Each of 10 tubes was filled from the bottom with $1 \mathrm{ml}$. using an 18-gauge needle, and the whole test was performed in a water-bath at $37^{\circ} \mathrm{C}$. The end-point was taken at the time for the blood in the last tube to clot, each being completely inverted at intervals of five minutes. The tubes were examined in the order in which they had been filled. In $96 \%$ the clotting time was 20 35 minutes; it was never under 15 or over 40 and the average was 26 minutes.

\section{Method of Investigation}

The blood coagulation times of new patients admitted to a large mental hospital were estimated. None of those investigated was physically ill and none gave a history of bleeding after operation. Advantage was taken of the fact that all patients admitted have blood taken for Wassermann and Widal tests, and the coagulation times were determined with these specimens of blood. The patients were not, therefore, inconvenienced. Those with difficult veins were excluded.

Test-tubes (not moistened with saline) measuring 3 in. by $\frac{1}{2}$ in. were filled from the bottom using $10-\mathrm{ml}$. syringes and 18-gauge needles. Blood was aspirated, with minimal venous trauma, into a syringe, which was then removed and a second one fitted on to the needle, which was maintained as motionless as possible in the vein. Clean needles were placed on each syringe and $1 \mathrm{ml}$. of blood was put into each tube ; in all cases blood from the second syringe was put into 10 tubes, but blood from the first was usually only put into five. When blood appeared in each syringe a stop-watch was started. The tubes were left undisturbed for five minutes and then examined by tilting at intervals of 30 seconds. They were examined in the order in which they had been filled, each succeeding one being left undisturbed until blood in the preceding one had clotted. In taking the specimens suction was never applied until the tip of the needle was inside the lumen of the vein.

\section{Results}

As there is a difference of opinion as to how the coagulation time should be read, results are given both as the average of the tubes and also as that of the last tube.

Early in the investigation it became apparent that even slight movement of the needle in the vein made the clotting time of blood in the second syringe more or less the same as that in the first, whereas the less movement permitted the greater was the difference between the two samples. This 
difference is shown in Table $\mathrm{I}$, which also shows that, depending upon the way in which the results were expressed, the longest times were 18-21 minutes.

TABLE I

COAGULATION TIMES (IN MINUTES) OF BLOOD IN FIRST AND SECOND SYRINGES

\begin{tabular}{|c|c|c|c|c|c|c|c|}
\hline \multicolumn{4}{|c|}{$\begin{array}{c}\text { No Perceptible Needle } \\
\text { Movement }\end{array}$} & \multicolumn{4}{|c|}{ Slight Needle Movement } \\
\hline \multicolumn{2}{|c|}{ 1st Syringe } & \multicolumn{2}{|c|}{ 2nd Syringe } & \multicolumn{2}{|c|}{ 1st Sy ringe } & \multicolumn{2}{|c|}{ 2nd Syringe } \\
\hline Average & $\begin{array}{l}\text { Last } \\
\text { Time }\end{array}$ & Average & $\begin{array}{l}\text { Last } \\
\text { Time }\end{array}$ & Average & $\begin{array}{l}\text { Last } \\
\text { Time }\end{array}$ & Average & $\begin{array}{l}\text { Last } \\
\text { Time }\end{array}$ \\
\hline $\begin{array}{c}9 \\
10 \\
10 \\
6 \\
13 \\
10 \\
12 \frac{1}{2} \\
13 \\
6 \\
9 \frac{1}{2} \\
7 \\
7 \\
12 \frac{1}{2} \\
6 \frac{1}{2} \\
9 \frac{1}{2} \\
5 \\
5 \\
5\end{array}$ & $\begin{array}{c}10 \\
10 \\
10 \\
6 \\
13 \\
10 \frac{1}{2} \\
13 \frac{1}{2} \\
14 \\
6 \\
10 \\
7 \\
8 \\
14 \\
6 \frac{1}{2} \\
9 \frac{1}{2} \\
5 \\
5 \\
5\end{array}$ & $\begin{array}{l}13 \\
15 \\
15 \\
13 \\
19 \\
17 \frac{1}{2} \\
16 \\
18 \\
11 \\
13 \\
11 \\
13 \\
17 \frac{1}{2} \\
11 \frac{1}{2} \\
13 \\
10 \\
11 \\
16\end{array}$ & $\begin{array}{l}14 \\
17 \\
15 \frac{1}{2} \\
14 \\
21 \\
19 \\
18 \\
21 \\
13 \\
15 \\
12 \\
14 \\
20 \frac{1}{2} \\
12 \\
13 \\
12 \\
11 \\
17\end{array}$ & $\begin{array}{c}8 \\
5 \\
12 \frac{1}{2} \\
8 \frac{1}{2} \\
13 \\
8 \frac{1}{2} \\
7 \\
9 \\
13 \\
15 \frac{1}{2} \\
9 \frac{1}{2} \\
10 \frac{1}{2}\end{array}$ & $\begin{array}{c}8 \frac{1}{2} \\
5 \\
14 \frac{1}{2} \\
8 \frac{1}{2} \\
13 \\
9 \\
8 \\
10 \\
15 \\
17 \\
9 \frac{1}{2} \\
12\end{array}$ & $\begin{array}{c}8 \\
5 \\
10 \\
9 \\
9 \frac{1}{2} \\
8 \\
7 \frac{1}{2} \\
10 \\
10 \\
15 \frac{1}{2} \\
9 \frac{1}{2} \\
13\end{array}$ & $\begin{array}{c}8 \\
5 \\
10 \\
10 \\
12 \\
8 \\
7 \frac{1}{2} \\
11 \\
10 \\
17 \\
9 \frac{1}{2} \\
13\end{array}$ \\
\hline
\end{tabular}

It should be made clear, however, that the 3 in. $\times \frac{1}{2}$ in. tubes which were used will have given different values from the standard $2 \frac{1}{2}$ in. $\times \frac{3}{8}$ in. tubes.

\section{Discussion}

The work of Allen and Attyah (1953) has been confirmed in so far as the clotting time of blood in the second syringe has been found to be longer than that in the first. It was difficult to keep the needle absolutely motionless in the vein, and I find it hard to believe that this ideal was realized by Allen and Attyah in every case.

Wright, Maizels, and Jepson (1952) state that " the dominant factor normally controlling the clotting time of whole blood is the concentration of thromboplastin." It is reasonable to infer that, in those cases in which the needle was moved in the vein while changing syringes, thromboplastin was liberated into the lumen thereby shortening the clotting time. Prothrombin consumption tests were not performed in the course of the present investigation. However, it is most unlikely that the patients with clotting times exceeding $15 \%$ minutes were all suffering from asymptomatic haemorrhagic diatheses with prolonged clotting? times. The "two-syringe" method shows thee great significance of venous trauma upon the result. It seems very doubtful if methods of determining the clotting time using capillary blood 0 are of any use, as contamination with thrombo-e plastin is so likely to occur. In a patient with $\vec{\circ}$ veins that are difficult to find, the intravenous tech nique will give results which are almost certainlyc too low. It is suggested that pathologists should always state in their reports whether the vein was? entered with ease or not ; the clinician will then be $e_{\omega}^{\infty}$ able to evaluate the result more accurately.

\section{Summary}

Estimations of the coagulation time, using $\vec{a}$ "two-syringe" modification of Lee and White' method, were performed on 30 physically norma patients newly admitted to a mental hospital. In 18 cases in which the technique was reasonablyo perfect, evidence was obtained that the coagulation ${ }^{\mathrm{N}}$ time of blood in the second syringe was longero than that in the first. The results were the sames in the 12 cases in which the needle was inadver tently moved slightly when the syringes were beingo changed. It is concluded that even slight injury to the intima of a vein liberates sufficient thrombo $\vec{\Rightarrow}$ plastin to shorten the coagulation time significantly Evidence is produced to show that the upper limits of the coagulation time of normal venous whole? blood is longer than that quoted in textbooks if care is taken to minimize the liberation of thromboplastin from the intima of the vein.

I wish to thank Dr. H. B. Miller for his encouragement to carry out research on his cases, and Dr. A. J. Shillitoe for his constructive criticism.

\section{REFERENCES}

Allen, G. W., and Attyah, A. M. (1953). J. Lab. clin. Med., 41, 767 Cummine, H., and Lyons, R. N. (1948). Brit. J. Surg., 35, 337. $\mathrm{N}$ Dutton, J. (1954). Brit. med. J., 1, 566

Friedman, I. A., Schwartz, S. Ö., and Vincenti, M. (1952). J. Amer.N med. Ass., 150, 83.

Lee, R. I., and White, P. D. (1913). Amer. J.med. Sci., 145, 495. N Wintrobe, M. M. (195i). Clinical Hematology, 3rd ed., p. 257.

Kimpton, London.
Wright, S. Maizels, M., and Jepson, J. B. (1952). Applied Physiology, 9th ed., p. 143. Oxford Univ. Press, London. 